\title{
Systemic chemotherapy with pronounced efficacy and neutropenia in a granulocyte-colony stimulating factor-producing advanced gastric neuroendocrine carcinoma
}

\author{
NOBUHIRO TSURUTA ${ }^{1}$, KOTOE TAKAYOSHI ${ }^{1}$, SHUJI ARITA ${ }^{1,2}$, TOMOMI AIKAWA $^{1}$, HIROSHI ARIYAMA ${ }^{1}$, \\ HITOSHI KUSABA ${ }^{1}$, KENOKI OHUCHIDA ${ }^{3}$, EISHI NAGAI ${ }^{3}$, KENICHI KOHASHI ${ }^{4}$, MINAKO HIRAHASHI ${ }^{4}$, \\ KYOKO INADOMI $^{1}$, MAMORU TANAKA ${ }^{1}$, KOSUKE SAGARA $^{1}$, YUTA OKUMURA ${ }^{1}$, KENTA NIO ${ }^{1}$, \\ MICHITAKA NAKANO ${ }^{1}$, MASAFUMI NAKAMURA $^{3}$, YOSHINAO ODA $^{4}$, KOICHI AKASHI $^{1}$ and EISHI BABA ${ }^{2}$ \\ ${ }^{1}$ Department of Hematology and Oncology, Kyushu University Hospital; ${ }^{2}$ Department of \\ Comprehensive Clinical Oncology, Faculty of Medical Sciences, Kyushu University; Departments of ${ }^{3}$ Surgery and Oncology, \\ and ${ }^{4}$ Anatomic Pathology, Graduate School of Medical Sciences, Kyushu University, Fukuoka 812-8582, Japan
}

Received December 25, 2015; Accepted February 23, 2017

DOI: $10.3892 / 01.2017 .6299$

\begin{abstract}
An advanced granulocyte-colony stimulating factor (G-CSF)-producing tumor is rare, and it exhibits leukocytosis in association with high serum G-CSF levels. A 67-year-old male with a 1-month history of bloody emesis and black stools was revealed to exhibit leukocytosis, anemia and a high serum concentration of G-CSF. During a gastrointestinal endoscopy, an ulcerating tumor was identified in the stomach. Computed tomography and a fluorodeoxyglucose-positron emission tomography scan demonstrated direct invasion of the gastric tumor into the transverse colon, regional lymphadenopathy, lung nodules and diffuse high uptake of FDG in bone marrow. The histological diagnosis was a G-CSF-producing neuroendocrine carcinoma (NEC) (tumor $4 \mathrm{~b}$, node 2, metastasis 1 , pulmonary, clinical stage IV). Systemic chemotherapy consisting of cisplatin and irinotecan was started. Common terminology criteria of adverse events grade 3 tumor lysis syndrome and gastric penetration appeared. Grade 4 neutropenia lasted for 10 days despite intensive G-CSF administration. Prominent shrinkage of the primary and the metastatic tumors was observed subsequent to 3 cycles of chemotherapy. Total gastrectomy and resection of the transverse colon were subsequently performed. Systemic chemotherapy was effective for a G-CSF-producing advanced gastric NEC with careful
\end{abstract}

Correspondence to: Professor Eishi Baba, Department of Comprehensive Clinical Oncology, Faculty of Medical Sciences, Kyushu University, 3-1-1, Maidashi, Higashi-ku, Fukuoka 812-8582, Japan

E-mail: e-baba@c-oncology.med.kyushu-u.ac.jp

Key words: gastric neuroendocrine carcinoma, granulocyte-colony stimulating factor-producing tumor, chemotherapy, adverse events, neutropenia monitoring and appropriate supportive care for severe adverse events.

\section{Introduction}

Granulocyte-colony stimulating factor (G-CSF) is a cytokine produced mainly by macrophages, fibroblasts and endothelial cells, which functions to induce maturation and proliferation of the precursor of neutrophils in the bone marrow and recruit them into the periphery (1). Production of G-CSF by non-hematological malignant cells is rarely observed. G-CSF-producing cancers have been reported in the lung, digestive organs and urinary bladder (2). The histological types of G-CSF-producing gastric cancers are often poorly differentiated carcinoma and undifferentiated carcinoma (3). In addition, G-CSF-producing tumors generally show an aggressive clinical course and poor prognosis.

Neoplasms of the various organs with neuroendocrine features have been recognized as neuroendocrine tumors (NETs), and their annual age-adjusted incidence was reported to be $\sim 5$ per 100,000 individuals (4). Neuroendocrine carcinoma (NEC) is a type of NET, which shows a pathologically high proliferation rate. NEC encompasses small cell NEC and large cell NEC (5). Small cell lung carcinoma (SCLC) is the most frequently identified type of NEC, and $33 \%$ of extrapulmonary small cell carcinomas have been reported to be of gastrointestinal origin (6). Since the standard treatment of extrapulmonary NECs (EPNECs) including gastric NECs has not been established, platinum-based combination chemotherapies are commonly selected, since the clinicopathological features of EPNECs are similar to those of SCLC (7). However, treatment effectiveness is limited, and the prognosis of EPNEC is poor. The median survival of patients with gastrointestinal NEC has been reported to be $\sim 13$ months (8).

There are a limited number of studies describing G-CSF-producing NECs $(9,10)$, and to the best of our knowledge, no G-CSF-producing advanced gastric NECs have been reported. Since the chemotherapy regimen for NEC may 
be affected by a high serum G-CSF concentration, careful supportive therapy is required. The present study presents the case of a male with a G-CSF-producing advanced gastric NEC, which was expected to have an aggressive clinical course. The patient was successfully treated with chemotherapy along with an appropriate supportive therapy.

\section{Case presentation}

A 67-year-old male with bloody emesis and black stools was referred by a physician to the Department of Hematology and Oncology, Kyushu University Hospital (Fukuoka, Japan) in April 2015. The patient had a history of smoking for 47 years and hypertension. The patient's temperature was $37.0^{\circ} \mathrm{C}$ when he was referred. The other vital signs of the patient were within normal limits, and his Eastern Cooperative Oncology Group (ECOG) performance status was 1. Upon physical examination, the bulbar conjunctiva appeared anemic. The laboratory results were as follows: White blood cells (WBC), $25,190 / \mu 1$ (neutrophils $90.8 \%$, lymphocytes $3.3 \%$, monocytes $4.9 \%$, eosinophils $0.3 \%$ and basophils of $0.3 \%$; normal levels: WBC 3300-8600/ml, neutrophils 40-70\%, lymphocytes $18-53 \%$, monocytes $2-12 \%$, eosinophils $1-4 \%$, and basophils 0-1\%); hemoglobin, $9.3 \mathrm{~g} / \mathrm{dl}$ (normal level 13.7-16.8 g/dl); platelets, $23.5 \times 10^{4} / \mu 1$ (normal level $15.8-34.8 \times 10^{4} / \mu 1$ ); C-reactive protein (CRP), $11.21 \mathrm{mg} / \mathrm{ml}$ (normal level $<0.14 \mathrm{mg} / \mathrm{ml}$ ); lactate dehydrogenase, 348 IU/1 (normal level 124-222 IU/1); neuron specific enolase (NSE), $75.3 \mathrm{ng} / \mathrm{ml}$ (normal level $<15.1 \mathrm{ng} / \mathrm{ml}$ ); pro-gastrin-releasing peptide (Pro-GRP), $54.4 \mathrm{pg} / \mathrm{ml}$ (normal level $<81.0 \mathrm{pg} / \mathrm{ml}$ ); and carcinoembryonic antigen $15.9 \mathrm{ng} / \mathrm{ml}$ (normal level $<3.2 \mathrm{ng} / \mathrm{ml}$ ). Liver and renal function was within normal limits. Computed tomography (CT) demonstrated that the gastric tumor had directly invaded the transverse colon, and perigastric lymph node swelling was also observed (Fig. 1A). Several small nodules in the lungs were also identified, which were suggested to be metastatic tumors rather than primary lung tumors (Fig. 1B). Fluorodeoxyglucose-positron emission tomography (FDG-PET)/CT scanning also revealed metabolically active lesions in the stomach and lymph nodes, and bones of the spine, scapulae, ribs, pelvis and femur, however it was negative for the multiple lung nodules (Fig. 1C). Bone marrow aspiration revealed hypercellular bone marrow with no malignant features. The WBC count increased gradually, but neither symptom nor medical finding suggesting infectious diseases was observed. Elevation of the serum G-CSF concentration (105 pg/ml; normal level $<38 \mathrm{pg} / \mathrm{ml}$ ) was thought to be the possible cause of the leukocytosis and serum CRP elevation. Upper gastrointestinal endoscopy revealed an ulcerating tumor in the middle of the stomach, which was similar to a primary epithelial tumor (Fig. 2A). Light microscopic examination of the endoscopic biopsy specimen from the gastric tumor was fixed by $10 \%$ formalin neutral buffer for $24 \mathrm{~h}$ at room temperature and stained with hematoxylin and eosin that revealed proliferation of carcinoma cells arranged in a sheet-like pattern (Fig. 2B). Immunohistochemical analyses demonstrated that these tumor cells were positive for synaptophysin (Fig. 2C) and CD56, focally positive for G-CSF (Fig. 2D), but negative for chromogranin A (Fig. 2E), indicating the presence of a neuroendocrine tumor. The MIB-1 labeling index was $70 \%$ (Fig. 2F). The final diagnosis was a G-CSF-producing neuroendocrine carcinoma (NEC) (T4bN2M1PUL, clinical stage IV).

Since the tumors were unlikely to be curatively resectable, systemic chemotherapy consisting of cisplatin $\left(60 \mathrm{mg} / \mathrm{m}^{2}\right.$, day 1 , every 28 days) and irinotecan $\left(60 \mathrm{mg} / \mathrm{m}^{2}\right.$, days 1,8 and 15, every 28 days) was started in May 2015. Tumor lysis syndrome (TLS) of common terminology criteria for adverse events (CTCAE) grade 3 in association with hyperkalemia and hyperuricemia appeared 4 days subsequent to the initiation of chemotherapy. TLS improved with a large infusion of normal saline. Grade 4 neutropenia appeared on day 7 and agranulocytosis appeared on day 11. Grade 4 neutropenia lasted for 10 days even with intensive G-CSF administration. Grade 3 febrile neutropenia was also observed, and the patient was treated with antibiotic and antimycotic drugs. Other severe adverse events experienced were grade 3 anemia, thrombocytopenia, fatigue and loss of appetite. Due to these adverse events, the administration of cisplatin and irinotecan on day 8 and 15 was stopped. The method of dose reduction followed the standard therapy for small cell lung cancer (11). The WBC count $(2,610 / \mu \mathrm{l})$ and serum G-CSF concentration $(13.7 \mathrm{pg} / \mathrm{ml})$ decreased to within normal limits prior to the beginning of the second cycle of chemotherapy.

The doses of cisplatin and irinotecan in the second cycles were decreased to $50 \mathrm{mg} / \mathrm{m}^{2}$, and were not administered on day 15 . Grade 4 neutropenia appeared on day 21 , however it recovered immediately. No tumor lysis syndrome occurred, however grade 2 vomiting was observed. The doses of cisplatin and irinotecan in the third cycles were decreased additionally to $40 \mathrm{mg} / \mathrm{m}^{2}$. Subsequent to 3 cycles of chemotherapy, the general condition of the patient improved markedly, and gastrointestinal endoscopy (Fig. 3A) and CT (Fig. 3B) demonstrated remarkable shrinkage of the primary gastric tumor in association with the penetration of the gastric wall at the ulcerative tumor. Lymph nodes were also reduced in size, however no marked change was observed in the lung nodules, suggesting that these were non-tumorous lesions (Fig. 3C). The patient underwent laparoscopic total gastrectomy with regional lymph adenectomy and partial resection of the transverse colon for curative intent in September 2015. Histological examination of the resected specimens revealed that the ulcerative residual tumor was composed of proliferating viable carcinoma cells with transmural fibrosis, necrosis and clear-cell degeneration, involving the whole thickness of gastric wall and invading around the adipose tissue, accompanied by a healed ulcer. Subsequent to recovery from the surgery, adjuvant chemotherapy with the same regimen is planned. A chest CT scan performed 3 months subsequent to total gastrectomy revealed no significant differences in the sizes of lung nodules.

\section{Discussion}

G-CSF-producing malignant solid tumors are not common, however G-CSF-producing tumors originating from lung, digestive organs and other organs have been reported (2). Leukocytosis, increased serum G-CSF concentrations, decreased leukocytes subsequent to surgery for the primary tumor, and positivity for G-CSF on immunohistochemical examination of tumor cells have been used as criteria for G-CSF-producing tumors (12). The present patient also 

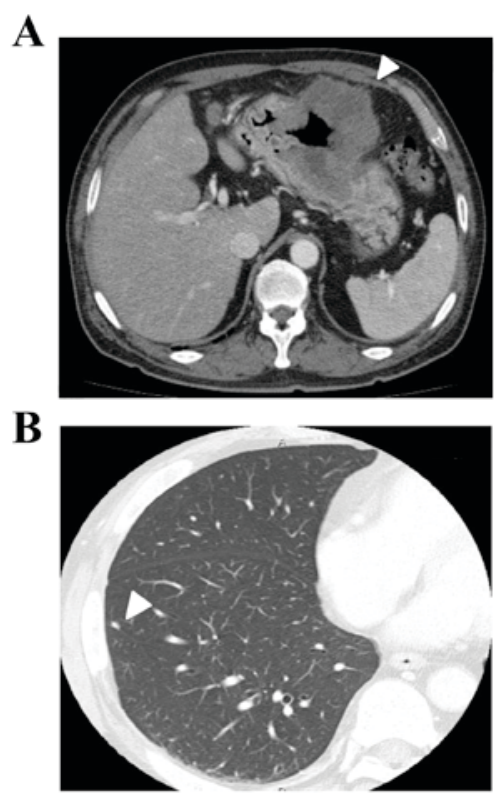

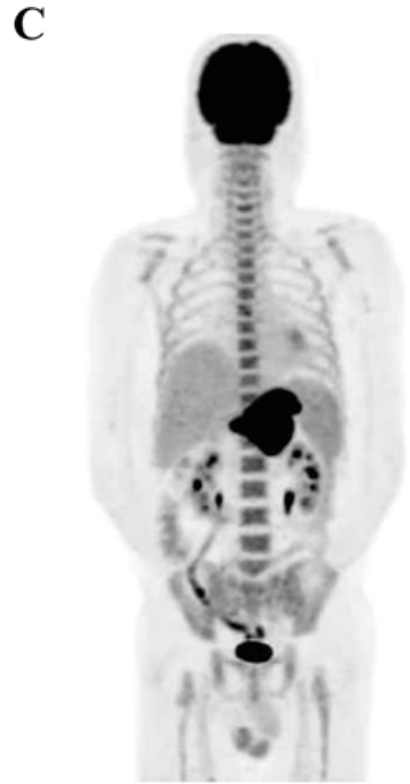

Figure 1. Images prior to chemotherapy: (A) CT of the abdomen shows the gastric tumor (arrow heads) and perigastric lymph node swelling. (B) CT of the lung nodule (arrow heads). (C) Fluorodeoxyglucose-positron emission tomography/CT scan shows metabolically active lesions in the stomach, lymph nodes, and bones of the spine, scapulae, ribs, pelvis and femur, but negative for multiple lung nodules. CT, computed tomography.
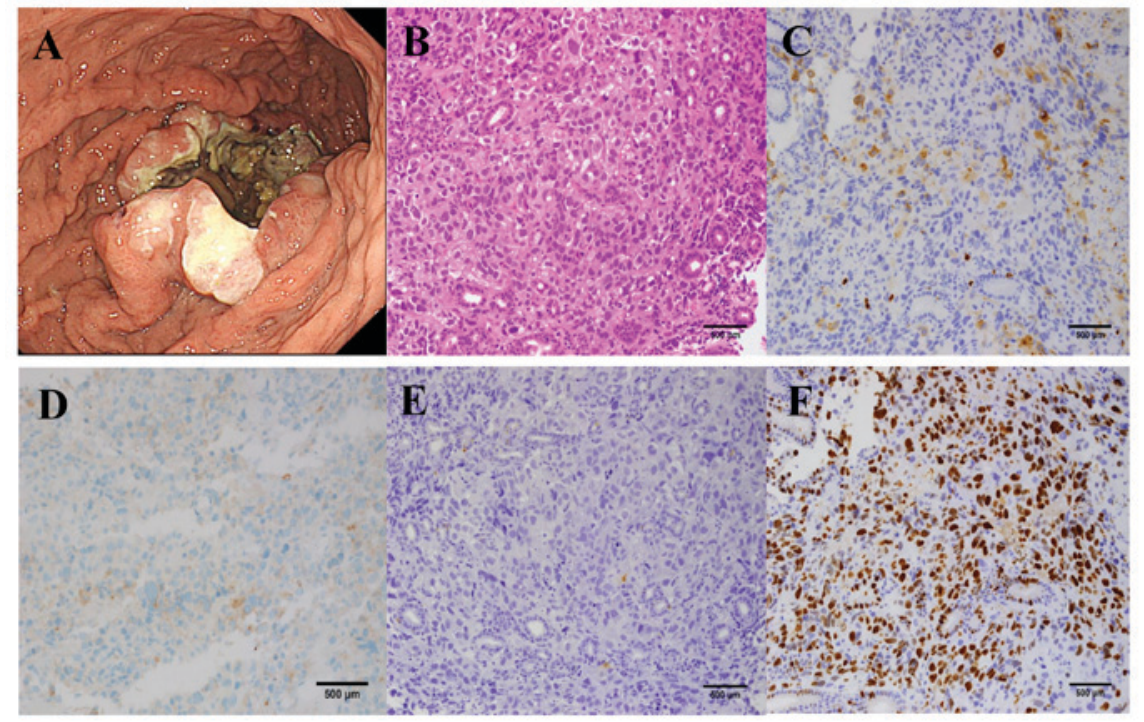

Figure 2. Images prior to chemotherapy. (A) Upper gastrointestinal endoscopy demonstrated an ulcerating tumor in the middle of the stomach. Histopathological examination of the gastric tumors (magnification, x200). (B) Hematoxylin and eosin staining (magnification, x200). Immunostaining of (C) synaptophysin (magnification, x200), (D) granulocyte colony-stimulating factor (magnification, x200), (E) chromogranin A (magnification, x200) and (F) MIB-1, monoclonal antibody reacting to the protein $\mathrm{Ki}-67$ of the primary tumor (magnification, $\mathrm{x} 200$ ).

exhibited some of these features and was diagnosed as an advanced G-CSF-producing gastric NEC.

The prognosis of G-CSF-producing tumors has generally been thought to be poor, however the reasons for this are unclear. One possible explanation is the autocrine loop of G-CSF/G-CSF receptors on the tumor cells. G-CSF-producing tumor cells may be stimulated via their own G-CSF receptors, and can also produce several types of cytokines including interleukin (IL)-6 (13), IL-1 $\beta$, and TNF- $\alpha$, which function to enhance tumor cell growth (14). Additionally, G-CSF can promote tumor growth by enhancing angiogenesis (15). Since a G-CSF-producing nature tended to be observed in poorly differentiated cancers, this histological feature may be associated with the poor prognosis of G-CSF-producing tumors.

Tumors with neuroendocrine features with a gastrointestinal origin have been diagnosed based on various nomenclatures. Since the World Health Organization (WHO) nomenclature published in 2010 is widely used, the present case was diagnosed according to it (5). NECs, including those of gastrointestinal origin, have been thought to be relatively sensitive to systemic chemotherapies (16). Yamaguchi et al (8) examined 154 patients with advanced gastrointestinal NECs treated with first-line chemotherapy, and demonstrated that each treatment, irinotecan plus cisplatin (IP) and etoposide 
Table I. G-CSF-producing neuroendocrine tumors in the literature.

\begin{tabular}{|c|c|c|c|c|c|c|c|c|}
\hline $\begin{array}{l}\text { Age/ } \\
\text { sex }\end{array}$ & $\begin{array}{l}\text { Primary } \\
\text { site }\end{array}$ & Stage & Histology & $\begin{array}{l}\text { WBC } \\
(/ \mathrm{ul})\end{array}$ & $\begin{array}{l}\text { G-CSF } \\
(\mathrm{ng} / \mathrm{ml})\end{array}$ & Treatment & $\begin{array}{l}\text { Chemotherapy } \\
\text { regimen }\end{array}$ & (Refs.) \\
\hline $79 \mathrm{M}$ & Esophagus & $\begin{array}{l}\text { T3N2M0, } \\
\text { Stage III }\end{array}$ & $\begin{array}{l}\text { Small cell } \\
\text { carcinoma }\end{array}$ & 15,180 & 52.4 & CRT & VP-16+CDDP & (9) \\
\hline $70 \mathrm{~F}$ & $\begin{array}{l}\text { Uterine } \\
\text { cervix }\end{array}$ & Stage IVb & $\begin{array}{l}\text { Small cell } \\
\text { carcinoma }\end{array}$ & 17,100 & 268 & CTx, RTx & CAJ, 5-FU & (10) \\
\hline $41 \mathrm{M}$ & Lung & $\begin{array}{l}\text { T3N0M0, } \\
\text { Stage IIIA }\end{array}$ & $\begin{array}{l}\text { Large cell } \\
\text { carcinoma }\end{array}$ & 38,400 & 105 & CTx, Surgery & CDDP+VDS & (17) \\
\hline $46 \mathrm{M}$ & Lung & $\begin{array}{l}\text { T2NOM0, } \\
\text { Stage IB }\end{array}$ & $\begin{array}{l}\text { Large cell } \\
\text { carcinoma }\end{array}$ & 40,400 & 318 & Surgery, Adjuvant CTx & $\begin{array}{l}\text { CBDCA+PTX, } \\
\text { Gefitinib }\end{array}$ & (18) \\
\hline $67 \mathrm{M}$ & Stomach & $\begin{array}{l}\text { T4bN2M1, } \\
\text { Stage IV }\end{array}$ & $\begin{array}{l}\text { Small cell } \\
\text { carcinoma }\end{array}$ & 25,190 & 105 & CTx, Surgery & CPT-11+CDDP & Present case \\
\hline
\end{tabular}

G-CSF, granulocyte colony-stimulating factor; WBC, white blood cell; M, male; T, tumor; N, node; M, metastasis; CRT, chemoradiotherapy; VP-16, Etoposide; CDDP, cisplatin; F, female; CTx, chemotherapy; RTx, radiotherapy; CAJ, cyclophosphamide+pirarubicin+carboplatin; 5-FU, 5-fluorouracil; VDS, vindesine; CBDCA, carboplatin; PTX, paclitaxel; CPT-11, irinotecan.

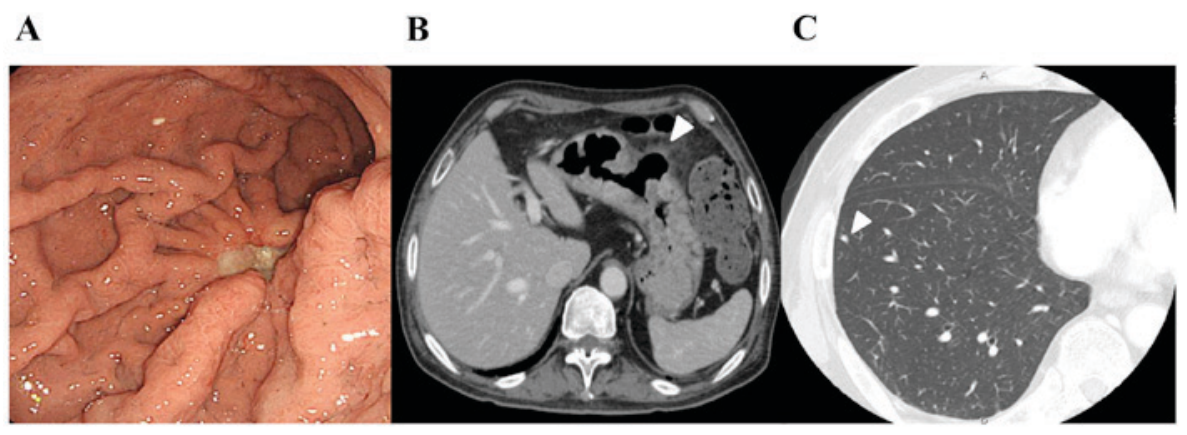

Figure 3. Images subsequent to chemotherapy. (A) Upper gastrointestinal endoscopy shows the tumor in the middle of the stomach, (B) CT of the abdomen shows the gastric tumor (arrow heads) and perigastric lymph node swelling; and (C) CT of the lung nodule (arrow heads). CT, computed tomography.

plus cisplatin, demonstrated equivalent efficacy with respect to the response rate (51 vs. $75 \%$ ), median PFS (5.4 vs. 4.9 months), and median OS (13.4 vs. 14.0 months) (8).

The present study identified four reports of G-CSFproducing neuroendocrine tumors in the literature (Table I). All cases demonstrated leukocytosis and high serum G-CSF concentrations. Immunohistochemical examinations were performed in two patients (with esophageal and cervical cancer), whereas the other two patients were diagnosed without immunohistochemical analyses as having large cell lung cancer $(9,10,17,18)$. Multidisciplinary therapy for these patients was tried, however long-term survival data were not provided. No severe adverse events in association with the systemic chemotherapies were reported, including severe neutropenia and tumor lysis syndrome. Since there are no reports of G-CSF-producing advanced gastric NECs, the present report is the first to demonstrate the effect of systemic chemotherapy for this disease. The patient was treated with the same IP regimen as for extended disease of small cell lung cancer (11). A favorable response was achieved, and the patient underwent surgery for curative intent.

TLS is common in hematological malignancies, however is rare in patients with solid tumors. Among solid tumors, TLS has been reported in association with small cell lung cancer. However, TLS cases are rare in patients who are diagnosed with extrapulmonary NEC (EPNEC) or extrapulmonary small cell carcinoma. Therefore, differences of the incidence and the clinical features of TLS between small cell lung cancer and EPNEC remain unclear. Tumors with susceptibility to TLS are thought to be those with rapid growth, a large tumor and sensitivity to chemotherapy. Elevation of serum uric acids, phosphate and creatinine, dehydration, hypotension and drugs affecting renal function are also risk factors of TLS (19). In the present case, specific features of the tumor may influence the occurrence of TLS. The increased concentration of G-CSF produced by tumor cells induces over-proliferation of granulocytes in the bone marrow and peripheral leukocytosis. Systemic chemotherapy during the condition in which neutrophils are greatly increased by G-CSF has been theoretically recognized to enhance bone marrow suppression due to damaging myeloid progenitor cells (20). Therapeutic use of $\mathrm{G}-\mathrm{CSF}$ products is required within $24 \mathrm{~h}$ after the chemotherapy to avoid enhanced bone marrow suppression (21). However, it was unclear whether chemotherapy for patients with continuously increased serum G-CSF concentrations could induce similar effects (20). No reports of G-CSF-producing tumor 
patients who suffered from severe neutropenia were identified. Notably, the present case demonstrated prominent adverse events induced by the systemic chemotherapy and required intensive supportive therapies. One of the possible reasons for the severe adverse events in the patient in the present case report may be a feature of the IP regimen, which tended to induce bone marrow suppression. A phase III clinical study for small cell lung cancer revealed that $25 \%$ of patients treated with the IP regimen exhibited CTCAE grade 4 neutropenia (11). The timing of chemotherapy in the condition of enhanced hematopoiesis by tumor-producing G-CSF and this feature of the IP regimen may be associated with the occurrence of serious adverse events in this patient.

At the onset of the severe neutropenia, C-GSF was intensively administered for therapeutic use. Since the serum G-CSF concentration at the point was not measured, it is not clear whether enough amount of intrinsic G-CSF remained to improve the neutropenia and the administered G-CSF was actually effective.

The gastric tumor of the present patient was resected subsequent to chemotherapy since the lung nodules were finally suggested to be non-tumorous lesions. Efficacy of conversion surgery may theoretically be expected in cases which demonstrate a high response rate of chemotherapy and possess limited metastatic sites. Additionally, efficacy of this strategy differs between the types of tumor. While conversion surgery could be one of the therapeutic strategies in colorectal cancer, the clinical meaning of it was not recognized in gastric cancer. Since favorable data of conversion surgery for gastric cancer has been accumulated, clinical studies assessing the efficacy of conversion surgery are ongoing (22). It remains unclear whether conversion surgery can be a standard therapy of EPNEC.

The present study demonstrated clear adverse events and favorable efficacy of systemic chemotherapy in a G-CSF-producing advanced gastric NEC patient. Since certain G-CSF-producing tumor patients may exhibit profound bone marrow suppression, as in the present case, careful observation and intensive supportive therapy are required.

\section{References}

1. Demetri GD and Griffin JD: Granulocyte colony-stimulating factor and its receptor. Blood 78: 2791-2808, 1991.

2. Kojima K, Nakashima F, Boku A, Muroishi Y, Nakanishi I and Oda Y: Clinicopathological study of involvement of granulocyte colony stimulating factor and granulocyte-macrophage colony stimulating factor in non-lymphohematopoietic malignant tumors accompanied by leukocytosis. Histol Histopathol 17: 1005-1016, 2002.

3. Kawaguchi M, Asada Y, Terada T, Takehara A, Munemoto Y, Fujisawa K, Mitsui T, Iida Y, Miura S and Sudo Y: Aggressive recurrence of gastric cancer as a granulocyte-colony stimulating factor-producing tumor. Int J Clin Oncol 15: 191-195, 2010.

4. Yao JC, Hassan M, Phan A, Dagohoy C, Leary C, Mares JE, Abdalla EK, Fleming JB, Vauthey JN, Rashid A and Evans DB: One hundred years after 'carcinoid': epidemiology of and prognostic factors for neuroendocrine tumors in 35,825 cases in the United States. J Clin Oncol 26: 3063-3072, 2008.

5. Bosman FT, Cameiro F and Hruban RH: Theise ND; WHO classification of tumors of the digestive system, 4th edition. WHO Press, Geneva, pp13-14, 2010.

6. Wong YN, Jack RH, Mak V, Henrik M and Davies EA: The epidemiology and survival of extrapulmonary small cell carcinoma in South East England, 1970-2004. BMC Cancer 9: 209, 2009.
7. Kulke MH, Shah MH, Benson AB III, Bergsland E, Berlin JD, Blaszkowsky LS, Emerson L, Engstrom PF, Fanta P, Giordano T, et al: Neuroendocrine tumors, version 1.2015. J Natl Compr Canc Netw 13: 78-108, 2015.

8. Yamaguchi T, Machida N, Morizane C, Kasuga A, Takahashi H, Sudo K, Nishina T, Tobimatsu K, Ishido K, Furuse J, et al: Multicenter retrospective analysis of systemic chemotherapy for advanced neuroendocrine carcinoma of the digestive system. Cancer Sci 105: 1176-1181, 2014

9. Sato Y, Takahashi Y, Nishiie K, Okubo S, Fujikaw K, Shintani N, Takada K, Sato Y, Takimoto R, Kato J and Niitsu Y: A case of granulocyte-colony stimulating factor producing small cell carcinoma of esophagus. Nihon Shokakibyo Gakkai Zasshi 102: 888-893, 2005 (In Japanese).

10. Watanabe A, Wachi T, Omi H, Nishii H, Ochiai K, Tanaka T and Endo Y: Granulocyte colony-stimulating factor-producing small-cell carcinoma of the uterine cervix: Report of a case. Diaqn Cytopathol 23: 269-274, 2000.

11. Noda K, Nishiwaki Y, Kawahara M, Negoro S, Sugiura T, Yokoyama A, Fukuoka M, Mori K, Watanabe K, Tamura T, et al: Irinotecan plus cisplatin compared with etoposide plus cisplatin for extensive small-cell lung cancer. N Engl J Med 346: 85-91, 2002.

12. Asano S, Urabe A, Okabe T, Sato N and Kondo Y: Demonstration of granulopoietic factor(s) in the plasma of nude mice transplanted with a human lung cancer and in the tumor tissue Blood 49: 845-852, 1977.

13. Tsuyuoka R, Takahashi T, Sasaki Y, Taniguchi Y, Fukumoto M, Suzuki A, Nakamura K, Kobayashi S, Kudo T and Nakao K: Colony-stimulating factor-producing tumours: Production of granulocyte colony-stimulating factor and interleukin-6 is secondary to interleukin-1 production. Eur J Cancer 30A: 2130-2136, 1994.

14. Matsumoto M, Nakayama $T$, Inoue $D$, Takamatsu $K$, Itotani $R$, Ishitoko M, Suzuki S, Sakuramoto M, Yuba Y, Yoshie O, et al: A pleomorphic carcinoma of the lung producing multiple cytokines and forming a rapidly progressive mass-like opacity. BMC Cancer 14: 588, 2014.

15. Morales-Arias J, Meyers PA, Bolontrade MF, Rodriguez N, Zhou Z, Reddy K, Chou AJ, Koshkina NV and Kleinerman ES: Expression of granulocyte-colony-stimulating factor and its receptor in human Ewing sarcoma cells and patient tumor specimens: Potential consequences of granulocyte-colony-stimulating factor administration. Cancer 110: 1568-1577, 2007.

16. Moertel CG, Kvols LK, O'Connell MJ and Rubin J: Treatment of neuroendocrine carcinomas with combined etoposide and cisplatin. Evidence of major therapeutic activity in the anaplastic variants of these neoplasms. Cancer 68: 227-232, 1991.

17. Teramachi M, Miyamoto N, Yamamoto Y, Sasaka T, Nakamura T and Kitamura F: A case of large cell carcinoma of the lung which is suspected of producing granulocyte colony-stimulating factor. Nihon Kyobu Shikkan Gakkai Zasshi 30: 1327-1332, 1992 (In Japanese).

18. Hasegawa S, Suda T, Negi K and Hattori Y: Lung large cell carcinoma producing granulocyte-colony-stimulating factor. Ann Thorac Surg 83: 308-310, 2007.

19. Gemici C: Tumor lysis syndrome in solid tumors. Clin Oncol (R Coll Radiol) 18: 773-780, 2006.

20. Amadori S, Suciu S, Jehn U, Stasi R, Thomas X, Marie JP, Muus P, Lefrère F, Berneman Z, Fillet G, et al: Use of glycosylated recombinant human G-CSF (lenograstim) during and/or after induction chemotherapy in patients 61 years of age and older with acute myeloid leukemia: Final results of AML-13, A randomized phase-3 study. Blood 106: 27-34, 2005.

21. Burris HA, Belani CP, Kaufman PA, Gordon AN, Schwartzberg LS, Paroly WS, Shahin S, Dreiling L and Saven A: Pegfilgrastim on the same day versus next day of chemotherapy in patients with breast cancer, non-small-cell lung cancer, ovarian cancer, and non-hodgkin's lymphoma: Results of four multicenter, double-blind, randomized phase ii studies. J Oncol Pract 6: 133-140, 2010.

22. Yoshida K, Yamaguchi K, Okumura N, Tanahashi T and Kodera Y: Is conversion therapy possible in stage IV gastric cancer: The proposal of new biological categories of classification. Gastric Cancer 19: 329-338, 2016. 